\title{
Kidney Ewing Sarcoma
}

National Cancer Institute

\section{Source}

National Cancer Institute. Kidney Ewing Sarcoma. NCI Thesaurus. Code C159208.

A rare Ewing sarcoma arising from the kidney. 